\title{
MANAGING TECHNOLOGY IN HEALTHCARE
}


MANAGEMENT OF MEDICAL TECHNOLOGY

\section{Eliezer Geisler}

University of Wisconsin

\section{Ori Heller}

University of Pennsylvania 


\title{
MANAGING TECHNOLOGY IN HEALTHCARE
}

\author{
edited by \\ Eliezer Geisler \\ and \\ Ori Heller
}

Kluwer Academic Publishers

Boston/London/Dordrecht 
Distributors for North America:

Kluwer Academic Publishers

101 Philip Drive

Assinippi Park

Norwell, Massachusetts 02061 USA

Distributors for all other countries:

Kluwer Academic Publishers Group

Distribution Centre

Post Office Box 322

3300 AH Dordrecht, THE NETHERLANDS

\section{Library of Congress Cataloging-in-Publication Data}

Geisler, Eliezer, 1942-

Managing technology in healthcare / Eliezer Geisler, Ori Heller.

p. $\quad$ cm. -- (Management of medical technology ; 1)

Includes bibliographical references and index.

ISBN-13: 978-1-4612-8614-1

e-ISBN-13: 978-1-4613-1415-8

DOI: $10.1007 / 978-1-4613-1415-8$

1. Medical technology--Management. I. Heller, Ori. II. Title. III. Series: Management of medical technology (Boston, Mass.) ; 1. R855.3.G45 1996

$610^{\prime} .28--\mathrm{dc} 20$

96-24589

CIP

Copyright (C) 1996 by Kluwer Academic Publishers

Softcover reprint of the harcover 1st edition 1996

All rights reserved. No part of this publication may be reproduced, stored in a retrieval system or transmitted in any form or by any means, mechanical, photocopying, recording, or otherwise, without the prior written permission of the publisher, Kluwer Academic Publishers, 101 Philip Drive, Assinippi Park, Norwell, Massachusetts 02061

Printed on acid-free paper. 


\section{DEDICATION}

To our parents:

Mrs. Chaya Geisler and the late Mordechai Geisler

and

Mrs. Tovi and Dr. Micha Heller 


\section{TABLE OF CONTENTS}

INTRODUCTION $\ldots \ldots \ldots \ldots \ldots \ldots \ldots \ldots \ldots \ldots \ldots \ldots \ldots \ldots \ldots$

\section{PART 1: ROLE OF TECHNOLOGY IN HEALTH CARE}

Chapter 1: Technology in Health Care: Definitions, Role and Mapping the Field (Eliezer Geisler and Ori Heller) . . . . . . . . . . . 1

Chapter 2: Forms of Technology and Effectiveness of Health Care Clinics (Ran Lachman) . . . . . . . . . . . . . . . . 11

Chapter 3: Technology-Based Service Innovation in Hospitals: The Role of Collective and Competitive Strategies (James Goes) . . . . . . . 33

\section{PART 2: ORGANIZATIONAL AND ECONOMIC EVALUATION}

Chapter 4: Cost Effectiveness and Cost Utility Analyses: Methods for the Non-Economic Evaluation of Health Care Programs and How We Can Do Better (Stephen Birch and Amiram Gafni) . . . . . 51

Chapter 5: Pacing and Outcomes: The Economic Implications (Chris Brown Mahoney) .................

Chapter 6: Management Technologies for Managing the Health Care Sector Technologies (Arnold Reisman) . . . . . . . . . . . . . . 103

Chapter 7: From Planning to the Market: Changes in Hospital Approaches to Medical Technology (Ann Lennarson Greer) . . . . . . . . . 127

\section{PART 3: $\quad$ MANAGEMENT PRACTICES}

Chapter 8: Forgotten Paths in Medicine: The Case of Chronic Kidney Disease (David Ahlstrum and Raghu Garud) . . . . . . . . . . . . . 155

Chapter 9: Re-engineering the Hospital (Aleda Roth and Susan Paul Johnson)

Chapter 10: The Necessity of Commercializing New Medical Technologies Before Clinical Use is Determined (John H. Friar) . . . . . . . 215

Chapter 11: International Comparison of the Approval of New Drugs (Stuart Schweitzer) ................. 231 


\section{LIST OF CONTRIBUTORS}

ELIEZER GEISLER

Department of Management

College of Business and Economics

University of Whitewater

Whitewater, WI 53190

\section{ORI HELLER}

Snider Entrepreneurial Center

University of Pennsylvania

The Wharton School

Vance Hall, 4th Floor

3733 Spruce Street

Philadelphia, PA 19104

\section{RAN LACHMAN}

Faculty of Management

Tel Aviv University

Tel Aviv, 69987, Israel

\section{JAMES GOES}

School of Business and Public

Administration

University of Alaska Southeast

11120 Glacier Highway

Juneau, Alaska 99801

\section{STEPHEN BIRCH}

Center for Health Economics and Dept. of Clinical Epidemiology

McMaster University

1200 Main Street West

Hamilton, ON L8N 3Z5, Canada

\section{AMIRAM GAFNI}

Center for Health Economics and

Department of Clinical

Epidemiology

McMaster University

1200 Main Street West

Hamilton, ON L8N 3Z5, Canada
CHRIS BROWN MAHONEY

Metropolitan State University

College of Management

730 Hennepin Avenue South

Minneapolis, MN 55403

ARNOLD REISMAN

Reisman and Associates

Shaker Heights, OH 44122

ANN LENNARSON GREER

Department of Sociology

University of Wisconsin-Milwaukee

Milwaukee, WI 53201

DAVID AHLSTROM

L. Stern School of Business

New York University

40 West 4 th Street, Tisch Hall

Room 7-30

New York, NY 10012

RAGHU GARUD

L. Stern School of Business

New York University

40 West 4th Street, Tisch Hall

New York, NY 10012

\section{ALEDA ROTH}

Kenan Flager Business School The University of North Carolina Campus Box 3490, Carroll Hall Chapel Hill, NC 27599

\section{SUSAN PAUL JOHNSON}

Kenan Flager Business School The University of North Carolina Campus Box 3490, Carroll Hall Chapel Hill, NC 27599 
NANCY M. SHORT

Duke University Medical Center

DUMC Box 3543

Durham, NC 27710

JOHN FRIAR

Graduate School of Management

Clark University

950 Main Street

Worcester, MA 01610

STUART SCHWEITZER

Department of Health Services

UCLA School of Public Health

Los Angeles, CA 90024 


\section{INTRODUCTION}

Eliezer Geisler and Ori Heller

It has become an accepted fact that technology plays a critical role in the management of health care systems, delivery and organizations. There is a growing crop of academic studies and practitioner anecdotal histories on the various attributes and behavior of management of technology in health care. In these times when health care is brought to the fore of the national agenda, it is highly important to systematically collect relevant knowledge in this area. This book is intended to introduce the reader to illustrative reports of studies, explorations, and policy statements in the management of technology in health care.

This book is the product of a unique association between a physician and a behavioral scientist, both with intense interest in managing technology. This book evolved as part of a program devised by the editors to foster the interdisciplinary field of managing technology in health care by promoting a bridge between $R \& D /$ technology and health care management scholars and practitioners. The book is an addition to academic publications, special issues, and potentially an independent scholarly journal. The key motivation behind the book was to provide exposure to varied publics of the exciting and innovative explorations that are occurring at the interface between technology management and health care management.

Clearly, no single book is able to satisfactorily expose the growing activity at the said interface. We hope that this will be a leading volume in a future string of such books on this and related topics. Also, we hope that this book will generate interest in the topic and will contribute to the acceleration of academic, as well as practitioner-oriented, studies and publications.

The complexity of the health care environment and the difficulties in managing technology in general (and in health care in particular) make this book a landmark attempt to create in-roads in a hitherto largely uncharted territory. The chapters in this book are merely representatives of the vast horizons that are open for scholarly pursuit in this area. 
This book has two main objectives. First, to provide the reader with an overview of the main issues of concern and the topics of study in managing technology in health care. Second, to offer the reader specific knowledge embedded in the eleven chapters of the book, covering a broad range of topics of interest to health care and to $R \& D /$ technology scholars and practitioners.

\section{THE AUDIENCES}

Since the book addresses the bridge between two disciplines, it may prove useful to several audiences. First, scholars in the area of health care management will benefit from the book as it introduces the role that managing technology plays in their area of interest. Second, scholars and students of R\&D/technology management will benefit from the book because it exposes them to a new area of application. Third, scholars who study management of service organizations will find this book useful as it relates to a major area of the service economy.

Practitioners will also find this book of acute interest. A fourth audience is managers of health care organizations, systems, hospitals, medical centers, and teaching hospitals. They will find the chapters in this book an intriguing and exciting addition to their daily struggle with technology and its impacts. Fifth, managers in the medical supply industry, such as equipment, pharmaceuticals, instruments and disposibles. These managers and their companies are an integral part of the technological component of the modern health care organization. Finally, this book will appeal to policy makers in the broad area of health care at the municipal, state, and federal levels. These executives will find the book to be a useful tool in sharpening their ideas and in fortifying the concepts and methods of technology management in health care.

\section{THE CONTENTS}

This book is structured in three parts. The first part includes three chapters and discusses the role of technology and the management of technology (MOT) in the health care environment.

The first chapter by Geisler and Heller introduces the reader to the concepts and definitions of MOT in health care. The authors present a matrix relating the five categories of technology in health care to the task of technology management. This matrix allows for an initial taxonomy of management of technology in health care.

The second chapter by Ron Lachman examines the effects of long-linked versus intensive forms of technology on the performance of health care clinics. The author concludes that patent involvement (high in the intensive form) is the key factor that explains the differences.

Chapter three by James Goes evaluates the influence of competitive and collective strategies on innovation in hospitals. The conclusion favors collective strategies as enhancers of the hospitals' understanding of environmental trends and 
access to external resources. The authors suggests that this study provides "some of the first empirical evidence that collective strategies actually enhance innovation."

The second part includes four chapters and is concerned with organizational and economic evaluations of technology and its management in health care organizations. In chapter four, Birch and Gafni assess the use of cost-effectiveness analysis and cost utility analysis in resources allocation in health care. They conclude that these methods fail to address the technical or allocative efficiency questions. In a seminal approach, they offer other methods which are derived from economic principles.

A different approach is offered by Chris Brown Mahoney in chapter five, where she analyzes the economic implications of different pacemaker technologies. She proposes the inclusion of such economic analysis into the decisions to select and to adopt treatment modes.

In chapter six, Reisman's contribution is in the development of a taxonomy of health care settings with technological components. This is a powerful organizational tool which also includes subfields of the area of management of technology, and operations research methodologies that have been applied in health care environments.

Finally, in this part, Ann Greer reports the results from 25 community hospitals which suggested that "advanced technological profile was essential to hospital survival and that cost saving could not be at the cost of a hospital's technical profile and image." This chapter offers some innovative in-roads into the analysis of the relation between management of technology and strategic changes in the management of hospitals and medical centers.

The third part includes four chapters that describe management practice in the management of technology in the health care sector. Chapter eight by Ahlstrum and Garud explores factors that influence and determine renal treatment practices in the U.S., as an example of the preference given by American physicians to technology-intensive treatments at the expense of other treatment modalities. They expose their powerful arguments in an evocative style and with crisp reasoning.

Chapter nine, by Roth and Johnson, addiesses the very relevant and current issue of re-engineering of technological processes in hospitals. They offer an excellent case for recasting the role of technology for strategic capabilities, thus showing in a sample of 65 hospitals that re-engineering in health care has a long way to go before it is adequately practiced. The implications of this chapter for academics and health care managers are far-reaching and very challenging.

John Friar, in chapter ten, uses the analysis of fifty years of development and use of ultrasound diagnostics as a case in point in his claim that new technologies should not be restricted to preapproved uses. This chapter is likely to generate much discussion, in view of the strong arguments Friar advances, and the far-reaching implications for the approval of medical technologies by regulatory agencies.

The final chapter, eleven, is by Stuart Schweitzer and also addresses approval of new pharmaceuticals. He compares approval patterns between the 
United States and France, and suggests that the approval process in both countries might be shortened.

The eleven chapters constitute a varied look at managing technology in health care. They address several issues of current concern, such as the economics, organization and re-engineering of technology and technological processes in health care organizations. We have tried to provide in this book a balance between theory and practice, and between normative and descriptive chapters.

As we said above, one volume cannot capture the variety and the complexity of this interdisciplinary field. It is our hope that this book will be a pioneer in a long chain of other forthcoming works on managing technology in health care.

\section{ACKNOWLEDGMENTS}

We are grateful to the reviewers of the chapters for their insights and helpful suggestions. We especially thank Gary Folven, our editor at Kluwer, whose support and belief in our project was an inspiration to us as we carve this new and exciting field of academic pursuit. We are very grateful to Janet Goranson for her invaluable help in the preparation of this book.

Eliezer Geisler

Evanston, Illinois
Ori Heller

Philadelphia, Pennsylvania

January, 1996 